Т.И.Мартыненко ${ }^{1,2}$, О.С.Параева ${ }^{1}$, С.В.Дронов ${ }^{3}$, Я.Н.Шойхет ${ }^{1}$

Оптимизация ранней нозологической верификации одышки легочного или сердечного генеза

1 - ГБоУ вПО "Алтайский государственный медицинский университет" Минздрава России: 656099, Барнаул, пр. Ленина, 40;

2 - КГБУЗ "Городская больница № 5": 656045, Барнаул, Змеиногорский тракт, 75;

3 - ФГБОУ ВПО "Алтайский государственный университет": 656049, Барнаул, пр. Ленина, 61

\title{
T.I.Martynenko, O.S.Paraeva, S.V.Dronov, Ya.N.Shoykhet \\ Improvement in early differentiation of breathlessness due to pulmonary or cardiac disease
}

\begin{abstract}
Summary
The aim of this study was early differentiation of breathlessness due to pulmonary or cardiac disease. The study was conducted in three stages. Firstly, we examined 359 patients aged 18 to 90 years with confirmed diagnosis of asthma $(n=134$, or $37.3 \%)$, COPD ( $\mathrm{n}=114$, or $31.8 \%)$, and chronic heart failure (CHF) not related to lung disease $(n=111$, or $30.9 \%)$. There were 154 males $(42.9 \%)$ and 205 females $(57.1 \%)$. We compared frequencies of P.M.Simon's "language of dyspnea" descriptors (1990) used by patients and excluded characteristics used equally often by patients with asthma, COPD or CHF. This allowed development a modified vocabulary of dyspnea (MVD) which consisted of 7 phrases and 6 clusters. Secondly, we developed a priori probability model to calculate probability of each diagnosis (PPD) using data from MVD and modified Bayesian classifier. Finally, we validated the PPD model with estimation of its sensitivity and specificity for asthma, COPD and CHF by comparing of a priori and a posteriori diagnoses. This analysis included a new cohort of 123 patients $(75(61.0 \%)$ males, $48(39.0 \%)$ females) aged 18 to 89 years with breathlessness as the leading symptom. All the patients fulfilled MVD before the diagnosis to be confirmed. Subsequent standard clinical examination revealed asthma in $47(38.2 \%)$, COPD in 46 (37.4\%), CHF in 30 (24.4\%) respondents.

Key words: breathlessness, chronic obstructive pulmonary disease, asthma, chronic heart failure, respiratory diseases.
\end{abstract}

\section{Резюме}

Целью исследования явилась оптимизация нозологической верификации одышки легочного или сердечного генеза. Исследование проводилось в 3 этапа. На 1-м этапе были обследованы пациенты $(n=359 ; 154(42,9 \%)$ мужчины и $205(57,1 \%)$ женщин) в возрасте от 18 до 90 лет с диагнозами: бронхиальная астма (БА) - 134 (37,3\%), хроническая обструктивная болезнь легких (ХОБЛ) - 114 (31,8 \%), хроническая сердечная недостаточность (XCH), не связанная с патологией легких, - 111 (30,9\%). Сравнительный анализ частоты встречаемости фраз из "Словника одышки" P.M.Simon et al. (1990) при каждой нозологической форме и исключение из опросника характеристик, одинаково часто регистрируемых при БА, ХОБЛ, ХСН, не связанной с патологией легких, по данным критерия Пирсона, позволили разработать "Модифицированный словник одышки" (МСО), состоящий из 7 фраз и 6 кластеров одышки. На 2-м этапе разработана модель расчета вероятности априорного диагноза (ВАД) с использованием данных МСО и модифицированного байесовского классификатора. На 3-м этапе проведена апробация модели ВАД, определение ее чувствительности и специфичности для БА, ХОБЛ и ХСН, не связанной с патологией легких, путем сравнения частоты совпадений априорного и апостериорного диагнозов. Для этого дополнительно были обследованы 123 пациента (75 (61,0\%) мужчин и $48(39,0 \%)$ женщин) в возрасте от 18 до 89 лет, основной жалобой которых являлась одышка. Заполнение МСО проведено методом сплошной выборки до верификации диагноза слепым методом. Последующее комплексное обследование позволило диагностировать БА у 47 (38,2 \%), ХОБЛ - у 46 (37,4 \%), ХСН, не связанную с патологией легких, - у $30(24,4 \%)$ респондентов.

Ключевые слова: одышка, хроническая обструктивная болезнь легких, бронхиальная астма, хроническая сердечная недостаточность, болезни органов дыхания.

Одышка - понятие, характеризуюшее субъективный опыт дыхательного дискомфорта, включающее различные качественные ощущения, различные по своей интенсивности [1].

Одышка является распространенным и часто изнурительным симптомом, который имеется у $50 \%$ больных, поступивших в экстренном порядке в стационары, и у $1 / 4$ пациентов, нуждающихся в медицинской помощи в амбулаторных условиях [2-4]. По результатам американского эпидемиологического исследования, 17 млн обращений к врачам происходит из-за одышки, причиной которой в $75 \%$ случаев являются заболевания сердца и легких $[2,3]$.
По данным А.Г. Чучалина, В.Н.Абросимова, С.Ю.Чи-

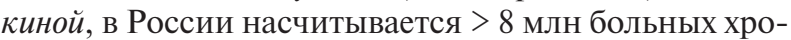
нической обструктивной болезнью легких (ХОБЛ), а бронхиальной астмой (БА) страдают около 7 млн человек [4-6]. В.Ю.Мареевым отмечено, что > 8 млн человек с четкими признаками хронической сердечной недостаточности $(\mathrm{XCH})$ обрашаются за медицинской помощью. Ведущим клиническим проявлением болезни во всех случаях (БА, ХОБЛ, ХСН) является одышка [5-8].

Одышка представляет собой субъективное ощущение, и именно словесное описание пациентом этого симптома лежит в основе диагностического 
поиска. С развитием системного анализа субъективных ощущений и описания больным чувства одышки, сформировалось понятие "язык одышки" [4, 9, 10]. Впервые научный подход к поиску закономерностей качественных характеристик нарушений дыхания осуществлено P.M.Simon et al. (1990) [10]. Это исследование стало началом создания "Словника одышки", в который включено 15 различных фраз, объединенных в 8 кластеров на основе описания ощущений чувства одышки у американских добровольцев [10].

При помощи качественной характеристики одышки проводится диагностика и дифференциация заболеваний определяется, какая из этих нозологических форм (НФ) вносит наибольший вклад в дыхательный дискомфорт больного при коморбидности $[4,11]$.

Целью настоящего исследования явилась оптимизация нозологической верификации одышки легочного или сердечного генеза. Для ее достижения проведено изучение и оценка особенностей одышки у больных БА, ХОБЛ, ХСН, не связанной с патологией легких, на основе "Словника одышки" P.M.Simon et al. (1990) [10].

\section{Материалы и методы}

Проведено когортное проспективное сравнительное исследование с применением метода слепого включения на III этапе.

Критерии включения: возраст старше 18 лет, установленный диагноз БА, ХОБЛ, ХСН, не связанный с патологией легких. Основной жалобой больных являлась одышка и комплаентность выполнению инструкций.

Критерии исключения: полиморбидность, онкологические заболевания, выраженная энцефалопатия.

Исследование состояло из 3 этапов:

- I - модификация "Словника одышки" P.M.Simon et al., (1990);

- II - разработка модели расчета вероятности априорного диагноза (ВАД) у пациента с одышкой легочного или сердечного генеза;

- III - оценка эффективности модели ВАД с определением ее чувствительности и специфичности для БА, ХОБЛ, ХСН, болезней органов дыхания (БОД) путем анализа частоты совпадений априорного и апостериорного диагнозов.

В исследование были включены больные с жалобами на одышку $(n=482 ; 280(58,1 \%)$ мужчин, 202 $(41,9 \%)$ женщины; возраст - 18-90 лет).

На I этапе обследованы больные $(n=359 ; 154$ (42,9 \%) мужчины; 205 (57,1 \%) женщин; возраст 18-90 лет) с известным диагнозом. ХОБЛ явилась причиной одышки у 114 (31,8 \%), БА - у 134 (37,3\%), $\mathrm{XCH}$, не связанная с патологией легких, - у 111 $(30,9 \%)$ больных. Пациенты с ХОБЛ и БА объединены в 1-й класс болезней (БОД), больные ХСН составили 2-й класс - болезни системы кровообращения (БСК), что позволило провести дополнительное исследование и сравнить "язык одышки" между БОД и БСК.

Пациентам предлагалось без ограничения времени и числа фраз отметить в "Словнике одышки" фразы, наиболее точно отражающие их ощущения в течение последних 2 нед.

Проведен одномоментный сравнительный анализ частоты встречаемости каждой фразы при изучаемых заболеваниях с расчетом критерия Пирсона. В данном исследовании критическое значение $\chi^{2}=5,99$ [12]. Полученный "Модифицированный словник одышки" (МСО) состоял из 7 фраз и 6 кластеров.

На II этапе с помощью модифицированного байесовского классификатора [12], определения коэффициентов дискриминантных прогностических функций и данных МСО была построена модель расчета ВАД у пациента с одышкой легочного или сердечного генеза.

На III этапе методом слепого включения пациентов проведена апробация модели ВАД. Главным критерием включения являлась жалоба пациентов на одышку, предположительно легочного или сердечного генеза. Пациентам, обратившимся к пульмонологу по поводу одышки, было предложено заполнить МСО. На момент анкетирования нозологический диагноз был неизвестен. Проанализировано 123 анкеты: 75 (61,0 \%) мужчин и $48(39,0 \%)$ женщин в возрасте 18-89 лет. Уточнение заключительного (апостериорного) диагноза осуществлялось в соответствии с национальными рекомендациями по диагностике БА, ХОБЛ, ХСН.

В последующем оценена частота совпадений априорного (рассчитанного в модели ВАД) и апостериорного (заключительного) диагнозов. Определены показатели чувствительности и специфичности модели ВАД для каждой НФ и класса болезней.

Обработка полученных данных проводилась по методике вариационной статистики с использованием компьютерных программ Biostat, SPSS 17 [13].

\section{Результаты}

Анализ частоты встречаемости отдельных фраз "Словника одышки" у больных БА, ХОБЛ, ХСН, не связанной с патологией легких, продемонстрировал отсутствие статистически значимых различий в частоте встречаемости 8 фраз и 2 кластеров одышки, которые были исключены из дальнейшего анализа (табл. 1). Таким образом, на I этапе исследования разработан МСО, состоящий из 7 фраз, частота встречаемости которых статистически достоверно различается у больных БА, ХОБЛ, ХСН (табл. 2). $\mathrm{MCO}$, в отличие от "Словника одышки", состоит из 6 кластеров и 7 фраз, которые характеризуют все основные качественные параметры одышки у больных БА, ХОБЛ и ХСН. Для каждого кластера типичной стала 1 фраза, за исключением кластера "неглубокое дыхание", который характеризуется 2 фразами. Из МСО были исключены 2 кластера: "частота" и "нехватка воздуха" и 3 относящиеся к ним фразы. 
Анализ частоты встречаемости фраз "Словника одышки" у больных БА, ХОБЛ, ХСН [10]

\begin{tabular}{|c|c|c|c|c|c|}
\hline \multirow[t]{2}{*}{ Кластеры одышки } & \multirow[t]{2}{*}{ Фразы одышки } & \multicolumn{3}{|c|}{ Заболевание, $n$ (\%) } & \multirow[t]{2}{*}{$\chi^{2}>5,99$} \\
\hline & & ХОБЛ, $n=114$ & $5 A, n=134$ & $\mathrm{XCH}, n=111$ & \\
\hline Частота & Я ощущаю свое частое дыхание* & $56(49,0)$ & $68(51,0)$ & $41(37,0)$ & 5,33 \\
\hline Выдох & Я не могу выдохнуть до конца & $63(55,0)$ & $67(50,0)$ & $34(31,0)$ & 15,36 \\
\hline \multirow[t]{3}{*}{ Неглубокое дыхание } & Мне трудно сделать вдох & $42(37,0)$ & $79(59,0)$ & $41(37,0)$ & 16,51 \\
\hline & Я не могу сделать глубокого вдоха & $55(48,0)$ & $72(54,0)$ & $38(34,0)$ & 9,64 \\
\hline & Мое дыхание поверхностное ${ }^{*}$ & $51(45,0)$ & $73(54,0)$ & $45(41,0)$ & 5,1 \\
\hline \multirow[t]{2}{*}{ Работа / усилие } & Я вынужден прикладывать дополнительное усилие, чтобы дышать & $51(45,0)$ & $71(53,0)$ & $29(26,0)$ & 18,46 \\
\hline & Мое дыхание нуждается в более напряженной работе & $44(39,0)$ & $46(34,0)$ & $36(32,0)$ & 1,0 \\
\hline \multirow[t]{2}{*}{ Удушье } & Я чувствую, как я задыхаюсь* & $57(95,0)$ & $75(56,0)$ & $46(41,0)$ & 5,14 \\
\hline & Я чувствую, как мое дыхание останавливается & $34(30,0)$ & $52(39,0)$ & $24(22,0)$ & 8,49 \\
\hline \multirow[t]{2}{*}{ Нехватка воздуха } & Я чувствую, что мне не хватает воздуха* & $77(68,0)$ & $85(63,0)$ & $61(55,0)$ & 3,94 \\
\hline & Я чувствую, что нуждаюсь в еще большем дыхании* & $53(46,0)$ & $57(43,0)$ & $48(43,0)$ & 0,43 \\
\hline \multirow[t]{2}{*}{ Сжатие } & Моя грудь стеснена & $36(32,0)$ & $59(44,0)$ & $33(30,0)$ & 6,62 \\
\hline & Моя грудь сдавлена* & $41(36,0)$ & $53(40,0)$ & $39(35,0)$ & 0,59 \\
\hline \multirow[t]{2}{*}{ Тяжесть } & Мое дыхание тяжелое & $67(59,0)$ & $88(66,0)$ & $40(36,0)$ & 22,82 \\
\hline & Я чувствую свое трудное дыхание * & $60(53,0)$ & $69(51,0)$ & $43(39,0)$ & 5,45 \\
\hline
\end{tabular}

Примечание: * - частота встречаемости фразы при БА, ХОБЛ, ХСН статистически недостоверна.

На II этапе осуществлено построение модели ВАД для определения вероятности нозологической причины одышки на основе модифицированного байесовского классификатора [12].

С целью построения прогностической функции рассчитана вероятность наличия НФ. Предпринята индикация взаимосвязи НФ с фразами МСО: "0" если фраза отсутствует в МСО при данной НФ; "1" если фраза присутствует в МСО при данной НФ. Введено допущение: у каждого вновь обследуемого пациента предполагается, что априорная вероятность каждой из 3 исследуемых НФ равнозначна и составляет $1: 3$.

Построение модели ВАД основано на анализе частоты встречаемости, количестве отмеченных фраз и их различных сочетаний с учетом полученных данных при известном диагнозе пациента, которые анализируются методами байесовского статистического анализа и позволяют вычислить вероятность НФ для каждого из пациентов. Была разработана специальная программа и создан рабочий лист электронных таблиц MS Excel.

Для построения модели введены обозначения: ХОБЛ $=$ НФ1, БА $=$ НФ2, ХСН = НФ3, БОД $=$ НФ4. С помощью созданного калькулятора рассчитываются цифровые параметры, наибольший из которых

Таблица 2

$\mathrm{MCO}$

\begin{tabular}{|r|l|c|l|} 
№ & Наименование кластера & № & Фразы, характеризующие кластер \\
I & Выдох & 1 & Я не могу выдохнуть до конца \\
\hline II & Неглубокое дыхание & 2 & Мне трудно сделать вдох \\
& 3 & 9 не могу сделать глубокого вдоха \\
\hline III & Работа / усилие & 4 & $\begin{array}{l}\text { Я вынужден прикладывать дополни- } \\
\text { тельное усилие, чтобы дышать }\end{array}$ \\
IV & Удушье & 5 & $\begin{array}{l}\text { 9 чувствую, как мое дыхание } \\
\text { останавливается }\end{array}$ \\
V & Сжатие & 6 & Моя грудь стеснена \\
VI & Тяжесть & 7 & Мое дыхание тяжелое \\
\hline
\end{tabular}

http://www.pulmonology.ru

будет соответствовать априорному диагнозу. Для определения принадлежности одышки пациента к БОД (ХОБЛ + БА) достаточно суммировать НФ1 и НФ2. Если значение НФ4 > НФ3, то возможно предполагать наличие у данного пациента БОД, а не БСК.

С целью иллюстрации применения модели ВАД в клинической практике приводится следующий пример: пациент, страдающий одышкой предположительно легочного или сердечного генеза, в предложенном МСО отметил следующие фразы: "я не могу выдохнуть до конца", "я чувствую, как мое дыхание останавливается", "моя грудь стеснена", "мое дыхание тяжелое". Врач в электронной таблице модели ВАД обозначает каждую фразу соотвествующим индикатором: "0" - фраза отсутствует, "1" фраза присутствует в МСО. С помощью программы рассчитывается вероятность НФ: ХОБЛ - 0,16, БА 0,06 и ХCH - 0,78 (табл. 3). Таким образом, для данного пациента априорным диагнозом является ХCH.

III этап исследования заключался в апробации разработанной модели ВАД в реальной клинической практике. МСО заполнялся пациентами $(n=123)$ с жалобой на одышку, предположительно легочного или сердечного генеза. После комплексного обследования заключительный (апостериорный) диагноз ХОБЛ установлен у 46 (37,4 \%) пациентов, БА - у 47 $(38,2 \%), \mathrm{XCH}$, не связанная с патологией легких у $30(24,4 \%)$.

При сопоставлении результатов модели ВАД и уточненной НФ установлено, что в группе пациентов с ХОБЛ совпадение априорного и апостериорного диагнозов отмечено у 22 из 39 больных, при БА у 32 из 43, при ХСН - у 24 из 41 пациента (табл. 4).

При анализе сопоставления априорного и апостериорного диагнозов продемонстрировано, что истинно положительные (ИП) результаты модели ВАД при БА получены у $32(68,1 \%)$ из 47 пациентов, истинно отрицательные (ИО) - у 65 (85,5 \%) из 76. 
Пример использования модели ВАД для верификации априорного диагноза

\begin{tabular}{|c|c|c|c|c|c|}
\hline \multirow[t]{2}{*}{ № } & \multirow[t]{2}{*}{ Фразы МСO } & \multirow[t]{2}{*}{ Индикаторы } & \multicolumn{3}{|c|}{ Доля пациентов* } \\
\hline & & & ХОБЛ & БА & $\mathrm{XCH}$ \\
\hline 1 & Я не могу выдохнуть до конца & 1 & 0,55 & 0,50 & 0,31 \\
\hline 2 & Мне трудно сделать вдох & 0 & 0,37 & 0,59 & 0,37 \\
\hline 3 & Я не могу сделать глубокого вдоха & 0 & 0,48 & 0,54 & 0,34 \\
\hline 4 & Я вынужден прикладывать дополнительное усилие, чтобы дышать & 0 & 0,45 & 0,53 & 0,26 \\
\hline 5 & Я чувствую, как мое дыхание останавливается & 1 & 0,30 & 0,39 & 0,21 \\
\hline 6 & Моя грудь стеснена & 1 & 0,32 & 0,44 & 0,30 \\
\hline 7 & Мое дыхание тяжелое & 1 & 0,59 & 0,66 & 0,36 \\
\hline
\end{tabular}

Примечание: * - доля от числа пациентов с конкретным заболеванием (их число принято за 1).

При ХОБЛ ИП результаты были у 22 (47,8 \%) из 46 больных, ИО - у 60 (77,9\%) из 77. При ХСН ИП результаты определены у $24(80,0 \%)$ из 30, ИО - у 76 $(81,7 \%)$ из 93 пациентов. При БОД ИП результаты получены у $76(81,7 \%)$ из 93, ИО - у $24(80,0 \%)$ из 30 больных.

Тестирование модели ВАД у пациентов с неверифицированной одышкой легочного или сердечного генеза продемонстрировало ее умеренную чувствительность $(47,8 \%)$ и высокую специфичность $(77,9 \%)$ для диагностики ХОБЛ (табл. 5). Высокочувствительна и высокоспецифична модель ВАД была в диагностике БА: $68,1 \%$ и 85,5 \% соответственно. Выявлены весьма высокая чувствительность $(81,7 \%)$ и специфичность (80,0 \%) модели ВАД в диагностике БОД у обследуемых пациентов. Высокой эффективностью модель ВАД обладает для верификации ХСН с чувствительностью 80,0 \% и специфичностью 81,7 \%.

Таким образом, на основании сопоставления частоты ИП и ИО результатов при сравнении априорного и апостериорного диагнозов установлено, что модель ВАД является высокочувствительной и высокоспецифичной для верификации классов БОД и ХСН (табл. 5). При БА модель ВАД демонстрирует высокие специфичность и чувствительность. Для

Таблица 4

Распределение пациентов по НФ с использованием априорного и апостериорного диагнозов

\begin{tabular}{|l|c|c|c|c|}
\multicolumn{1}{r|}{ Диагноз } & \multicolumn{3}{|c|}{ Апостериорный } & \multirow{2}{*}{ Всего } \\
\cline { 1 - 2 } \multicolumn{1}{|c|}{ Априорный } & БА & ХОБЛ & ХСH & \\
ХОБЛ & 12 & 22 & 5 & 39 \\
БА & 32 & 10 & 1 & 43 \\
ХСН & 3 & 14 & 24 & 41 \\
Всего & 47 & 46 & 30 & 123 \\
\hline
\end{tabular}

Таблица 5

Эффективность модели ВАД для верификации генеза одышки

\begin{tabular}{|l|r|c|c|c|}
\hline \multirow{2}{*}{ Критерий эффективности, \% } & \multicolumn{4}{|c|}{ Заболевание } \\
\cline { 2 - 5 } & БА & ХОБЛ & БОД & ХСН \\
\hline Чувствительность & 68,1 & 47,8 & 81,7 & 80,0 \\
\hline Специфичность & 85,5 & 77,9 & 80,0 & 81,7 \\
\hline
\end{tabular}

ХОБЛ модель ВАД, напротив, высокоспецифична и умеренно чувствительна.

\section{Обсуждение}

Дифференциальная диагностика генеза одышки первый и наиважнейший этап консультации специалиста, от которого зависит дальнейший алгоритм обследования и лечения пациента. Немаловажным является то, какими возможными инструментами обладает врач для решения этой задачи.

Один из инструментов для описания одышки основан на описании ее интенсивности, качества и выраженности дискомфорта - "язык одышки", состоящий из 15 различных описаний ощущений одышки [10]. С его помощью проводится диагностика у больных с конкурентными заболеваниями и выделяется состояние, вносящее наибольший вклад в дыхательный дискомфорт больного [1, 14, 15]. Но эта диагностика описана лишь на основании 1 характеристики одышки. Проведенные ранее исследования были направлены в основном на определение чувствительности и специфичности отдельных фраз "Словника одышки" для ХОБЛ и БА. Так, по данным [16], чувствительность и специфичность ощущения "сжатие грудной клетки" для БА составляет $86 \%$ и $69 \%$ соответственно, а для ХОБЛ - $7 \%$ и $64 \%$ соответственно. Другое описание - "я не могу сделать глубокий вдох" - высокоспецифично для ХОБЛ (72\%) и менее специфично - для БА (61\%), но недостаточно чувствительно для обоих заболеваний (37\% и $50 \%$ соответственно) [16].

Впервые предпринят комплексный подход для определения характерных паттернов качественных характеристик одышки при БА, ХОБЛ, ХСН, не связанной с патологией легких, а также класса БОД. Проведена дифференциальная диагностика генеза одышки. Путем сравнения частоты встречаемости отдельных фраз "Словника одышки" при БА, ХОБЛ, $\mathrm{XCH} \mathrm{и} \mathrm{исключения} \mathrm{из} \mathrm{опросника} \mathrm{фраз,} \mathrm{имеющих}$ одинаковую частоту при этих заболеваниях, разработан МСО, состоящий из 7 фраз, соответствующих 6 кластерам качественной характеристики одышки. Сокращение анкеты почти в 2 раза значительно упрощает общение с пациентом, уменьшает длитель- 
ность визита, повышает приверженность больных обучению, лечению и самоконтролю. МСО является основой для создания модели ВАД, которая позволяет врачу уже при 1-м общении с пациентом определить априорный диагноз как причину одышки в конкретной клинической ситуации. МСО и модель ВАД - новые инструменты для дифференциальной диагностики одышки у больных БА, ХОБЛ, ХСН и БОД. Они просты, доступны и эффективны для ранней верификации диагноза на этапе, предшествующем специализированным клинико-лабораторным и инструментальным методам исследования.

\section{Заключение}

Путем изучения анализа частоты встречаемости фраз "Словника одышки" при БА, ХОБЛ, ХСН выявлено, что "язык одышки" специфичен как для различных НФ, так и классов болезней: органов дыхания или сердечно-сосудистой системы. МСО и модель ВАД могут служить первичными инструментами для ранней дифференциации одышки легочного или сердечного генеза на этапе первичной медицинской помощи.

С учетом сравнительного анализа частоты встречаемости отдельных фраз "языка одышки" у больных БА, ХОБЛ, ХСН, не связанной с патологией легких, разработан МСО, включающий 7 фраз, продемонстрировавших статистически достоверные различия между исследуемыми НФ: "я не могу выдохнуть до конца", "мне трудно сделать вдох", "я не могу сделать глубокого вдоха", "я вынужден прикладывать дополнительное усилие, чтобы дышать", "я чувствую, как мое дыхание останавливается", "моя грудь стеснена", "мое дыхание тяжелое".

Разработанная модель ВАД позволяет начать раннюю дифференциальную диагностику генеза одышки с определением априорного диагноза на этапе первичной медицинской помощи.

Модель ВАД является эффективной для предварительной диагностики БА и ХОБЛ: высокая чувствительность метода для верификации БА - 68,1 \%, умеренная для ХОБЛ - 47,8 \% и высокая ее специфичность в диагностике БА и ХОБЛ $-85,5 \%$ и 77,9\% соответственно. Модель ВАД высокочувствительна и высокоспецифична для дифференциации классов БОД и ХСН.

\section{Литература}

1. Parshall M.B., Schwartzstein R.M., Adams L. et al. American Thoracic Society Committee on Dyspnea. An official American Thoracic Society statement: update on the mechanisms, assessment, and management of dyspnea. Am. J. Respir. Crit. Care Med. 2012; 185 (4): 435.
2. Desbiens N.A., Mueller-Rizner N., Connors A.F. The relationship of nausea and dyspnea to pain in seriously ill patients. Pain 1997; 71: 149-156.

3. Kroenke K., Arrington M.E., Mangelsdorff A.D. The prevalence of symptoms in medical outpatients and the adequacy of therapy. Arch. Intern. Med. 1990; 150: 1685-1689.

4. Чучалин А.Г. Одышка: патофизиологические и клинические аспекты. Рос. мед. журн. 2006; 5: 52-55.

5. Чучалин А.Г. (ред.). Респираторная медицина. М.: ГЭОТАР-Медиа; 2007. 407-418.

6. Чикина С.Ю. Принципы оценки одышки в практике пульмонолога. Атмосфера. Пульмонол. и аллергол. 2006; 2: $24-30$.

7. Мареев В.Ю., Агеев Ф.Т., Арутюнов Г.П. Национальные рекомендации ВНОК и ОССН по диагностике и лечению ХCH (III пересмотр). Сердеч. недостат. 2009; 2 (10): 64-103.

8. Laveneziana P., Lotti P., Coli C. et al. Mechanisms of dyspnoea and its language in patients with asthma. Eur. Respir. J. 2006; 27: 742-747.

9. Elliott M.W., Adams L., Cockcroft A. et al. The language of breathlessness: use of verbal descriptors by patients with cardiopulmonary disease. Am. Rev. Respir. Dis. 1991; 144: 826-832.

10. Simon P.M., Schwartzstein R.M., Weiss J.W. et al. Distinguishable types of dyspnea in patients with shortness of breath. Am. Rev. Respir. Dis. 1990; 142: 1009-1014.

11. Siafacas N.M., Schiza S., Xirouhaki N. et al. Is dyspnoea the main determinant of quality of life in the failing lung? A review. Eur. Respir.Rev. 1997; 42 (7): 53-56.

12. Дронов С.В. Многомерный статистический анализ. Барнаул: Алтайский гос. ун-т; 2006.

13. Медико-биологическая статистика: Пер. с англ. под ред. Н.Е.Бузикашвили, Д.В.Самойлова М.; 1999.

14. Официальный документ Американского торакального общества. Одышка: механизмы, оценка, лечение. Консенсус. Пульмонология 2005; 2: 9-34.

15. Scano G., Stendardi L., Grazzini M. Understanding dyspnoea by its language. A review. Eur. Respir. Rev. 2004; 24: 186-199.

16. Чикина С.Ю., Трушенко Н.В. Как понять "язык одышки"? Атмосфера. Пульмонол. и аллергол. 2012; 4: 35-37.

\section{Информация об авторах}

Мартыненко Татьяна Ивановна - д. м. Н., профессор, руководитель Алтайского краевого пульмонологического центра, КГБУЗ "ГБ № 5 , г. Барнаул", кафедра терапии и семейной медицины ФПК и ППС ГБОУ ВПО "АГМУ" Минздрава России; тел.: (3852) 68-85-12; e-mail: rtppul @ab.ru

Параева Ольга Сергеевна - врач-пульмонолог пульмонологического отделения № 1 КГБУЗ "ГБ № 5, г. Барнаул"; тел.: (3852) 68-85-59; e-mail: olgaparaeva@mail.ru

Дронов Сергей Вадимович - к. Ф.-м. н., доцент кафедры математического анализа, ФГБОУ ВПО "ААГМУ"; тел.: (3852) 36-70-18; e-mail: dsv @math.asu.ru

Шойхет Яков Нахманович - д. м. н., член-корр. РАМН, профессор, зав. кафедрой факультетской хирургии им. И.И. Неймарка с курсом хирургии ФПК и ППС ГБОУ ВПО "АГМУ" Минздрава России; тел. / Факс: (3852) 68-50-23; e-mail: starok100@mail.ru

Поступила 27.12.13 () Коллектив авторов, 2014 удК 616.24-008.7-07 